\title{
Single-group Study to Explore the Optimal Management of Neuropathic Scoliosis Caused by Neural Axis Abnormalities Based on its Clinical Features
}

\author{
Hiroshi Kuroki ${ }^{*}$, Naoki Inomata, Hideaki Hamanaka, Etsuo Chosa and Naoya Tajima \\ Department of Orthopaedic Surgery, University of Miyazaki Faculty of Medicine 5200, Kihara Kiyotake Miyazaki, 889- \\ 1692 Japan
}

\begin{abstract}
Although it is not easy to differentiate neuropathic scoliosis caused by neural axis abnormalities (NAAs) from idiopathic scoliosis for lack of neurological signs, neuropathic scoliosis caused by NAAs has some specific clinical findings. The purpose of this study was to investigate the characteristics of neuropathic scoliosis caused by NAAs and to discuss the essential points of diagnosis and treatment. From 1998 through 2008, 622 new patients visited our scoliosis outpatient clinic. Of those, 12 patients with neuropathic scoliosis caused by NAAs diagnosed by cervical MRI were involved in this study. They included 5 boys and 7 girls with a mean age of 10 years and 5 months. We investigated the relationship of NAAs, treatment methods for scoliosis, and effects of neurosurgical treatment for prognosis of outcome. There were 10 cases of syringomyelia with Chiari malformation type I, 1 case of syringomyelia alone, and 1 case of spinal cord tumor. Surgery was performed in 3 cases, an under arm brace was prescribed in 6 cases, and observation was selected in 3 cases. Scoliotic curves were improved in 4 out of the 11 cases on whom neurosurgical intervention for the relationship of NAAs were performed. The Cobb angles before surgery of these 4 cases were less than $30^{\circ}$ and 3 of the 4 cases were 8 years old or less. We would emphasize that early treatment for the relationship of NAAs at younger age $(\leq 8 \mathrm{yrs})$ and before curve progression $\left(<30^{\circ}\right)$ should be actively enforced for favorable prognosis of neuropathic scoliosis caused by NAAs.
\end{abstract}

Keywords: abdominal skin reflex, Chiari malformation, magnetic resonance imaging (MRI), neural axis abnormality, neuropathic scoliosis, syringomyelia.

\section{INTRODUCTION}

Neuropathic scoliosis caused by neural axis abnormalities (NAAs) often lacks neurological signs and expresses the spinal deformity as the only symptom [1-3]. Accordingly, it is not easy to differentiate neuropathic scoliosis caused by NAAs from idiopathic scoliosis. However, neuropathic scoliosis caused by NAAs has some specific clinical findings, for example; abnormality of abdominal skin reflex $[1,4]$, infantile or juvenile onset [5-8], atypical curve pattern [1, 9-11], thoracic hyperkyphosis [12] and so on.

The purpose of this retrospective study was to investigate the characteristics of neuropathic scoliosis caused by NAAs and to discuss the essential points of diagnosis and treatment for such kind of pathological condition.

\section{MATERIALS AND METHODS}

From 1998 through 2008, 622 new patients visited our scoliosis outpatient clinic. Of those, 12 patients $(1.9 \%)$ with neuropathic scoliosis caused by NAAs diagnosed by cervical MRI were involved in this study. They included 5 boys and 7 girls ranging in age from 5 years 4 months to 17 years 1 month, with a mean age of 10 years and 5 months.

\footnotetext{
*Address correspondence to this author at the Department of Orthopaedic Surgery, University of Miyazaki Faculty of Medicine, 5200, Kihara Kiyotake Miyazaki, 889-1692 Japan; Tel: 81-985-85-0986; Fax: 81-985-84-2931;

E-mail: hiroshik@med.miyazaki-u.ac.jp
}

We investigated the relationship of NAAs, detection of scoliosis, treatment methods for scoliosis and the clinical course, surgeries for NAAs and their effects for scoliosis, and clinical features; including ages of scoliosis detection, gender, curve pattern represented by King classification [13], curve magnitude assessed by Cobb angle, thoracic kyphosis measured between $\mathrm{T} 2$ and T12, and neurological findings. Further, 272 cases of idiopathic scoliosis patients, whose Cobb angles were more than $25^{\circ}$, detected during same period were set up as a control group. Then, clinical features were compared between neuropathic scoliosis caused by NAAs and idiopathic scoliosis. The clinical course of the treatment for scoliosis was considered progression if more than $5^{\circ}$ curvature increase occurred and improvement if more than $5^{\circ}$ curvature decrease occurred. Statistical analysis was performed using a two-tailed unpaired $t$-test and Chi square test. $\mathrm{P}<0.05$ level was considered statistically significant.

Written informed consent was obtained from the patients for publication of this report. And all procedures were in accordance with the Helsinki declaration.

\section{RESULTS}

There were 10 cases of syringomyelia with Chiari malformation type I, 1 case of syringomyelia alone, and 1 case of spinal cord tumor. With respect to detection of scoliosis, 5 cases were pointed out by other persons, 3 cases were discovered by school screening, and 4 cases were indicated 
Table 1. Clinical Data of Each Patient

\begin{tabular}{|c|c|c|c|c|c|c|c|}
\hline Case & $\begin{array}{c}\text { Age at Scoliosis } \\
\text { Diagnosis }(y \mathbf{y r}+\mathbf{m o})\end{array}$ & Gender & $\begin{array}{l}\text { Scoliosis } \\
\text { Pattern } \\
\text { (King) }\end{array}$ & NAAs & Occasion of Scoliosis Detection & $\begin{array}{c}\text { Treatment for } \\
\text { Scoliosis (Initial) }\end{array}$ & $\begin{array}{l}\text { Treatment for } \\
\text { Scoliosis (Final) }\end{array}$ \\
\hline 1 & $15+5$ & M & III & Chiari type I \& syrinx & pointed out by teacher & brace & brace \\
\hline 2 & $12+8$ & $\mathrm{~F}$ & III & Chiari type I \& syrinx & pointed out by parents & surgery & surgery \\
\hline 3 & $8+1$ & M & R-III * & spinal tumor & nonscheduled med exam & observation & observation \\
\hline 4 & $5+11$ & $\mathrm{~F}$ & $\mathrm{R}-\mathrm{I} *$ & Chiari type I \& syrinx & pointed out by parents & brace & brace \\
\hline 5 & $5+8$ & $\mathrm{~F}$ & III & Chiari type I \& syrinx & nonscheduled med exam & brace & surgery \\
\hline 6 & $7+11$ & $\mathrm{~F}$ & III & Chiari type I \& syrinx & nonscheduled med exam & brace & surgery $* *$ \\
\hline 7 & $17+1$ & M & R-III * & Chiari type I \& syrinx & school screening & surgery & surgery \\
\hline 8 & $15+8$ & $\mathrm{~F}$ & IIB & Chiari type I \& syrinx & school screening & surgery & surgery \\
\hline 9 & $11+3$ & $\mathrm{~F}$ & R-III * & syrinx & school screening & brace & surgery \\
\hline 10 & $14+3$ & M & R-III * & Chiari type I \& syrinx & pointed out by parents & observation & observation \\
\hline 11 & $5+7$ & $\mathrm{~F}$ & III & Chiari type I \& syrinx & nonscheduled med exam & observation & brace \\
\hline 12 & $5+4$ & M & $\mathrm{V}$ & Chiari type I \& syrinx & pointed out by parents & brace & brace \\
\hline
\end{tabular}

NAAs: neural axis abnormalities

* R: atypical inverted curve (left thoracic, right lumbar)

** case 6: growing rod

Table 1. contd...

\begin{tabular}{|c|c|c|c|c|c|}
\hline \multirow[b]{2}{*}{ Case } & \multirow[b]{2}{*}{ Surgery for NAAs } & \multirow{2}{*}{$\begin{array}{l}\text { Effect of Surgery for } \\
\text { NAAs to Scoliosis }\end{array}$} & \multicolumn{2}{|c|}{ Neurological Findings } & \multirow{2}{*}{$\begin{array}{c}\text { Thoracic } \\
\text { Kyphosis }\left(^{\circ}\right)\end{array}$} \\
\hline & & & Abdominal Skin Reflex & Neurological Symptom & \\
\hline 1 & $\mathrm{FMD}+\mathrm{SS}$ shunt & none & $--/-$ & motor dysfunction of right arm & 27 \\
\hline 2 & FMD & $\mathrm{N} / \mathrm{A}$ & $++/++$ & none & 34 \\
\hline 3 & tumorectomy & yes & $++/++$ & acute left hemiplegia & 35 \\
\hline 4 & FMD+SS shunt & yes & $--/++$ & gait abnormality & 37 \\
\hline 5 & FMD + SS shunt & none & $--/++$ & none & 38 \\
\hline 6 & FMD & none & $--1--$ & none & 43 \\
\hline 7 & FMD + SS shunt & $\mathrm{N} / \mathrm{A}$ & $++/--$ & none & 48 \\
\hline 8 & FMD & N/A & $--1--$ & none & 44 \\
\hline 9 & none & N/A & $++1--$ & none & 41 \\
\hline 10 & FMD & yes & $+-1--$ & none & 37 \\
\hline 11 & FMD & ues & $--/++$ & none & 54 \\
\hline 12 & FMD & none & $++/-$ & none & 47 \\
\hline
\end{tabular}

N/A: surgery for scoliosis was performed within 1 year after surgery for original NAAs

Table 1. contd...

\begin{tabular}{|c|c|c|c|c|c|c|c|}
\hline \multirow[b]{2}{*}{ Case } & \multicolumn{5}{|c|}{ Curve Magnitude $\left(^{\circ}\right)$} & \multirow{2}{*}{$\begin{array}{l}\text { Length of Follow- } \\
\text { Up after Surgery } \\
\text { for NAAs }\end{array}$} & \multirow{2}{*}{$\begin{array}{l}\text { Length of Follow- } \\
\text { Up after Surgery } \\
\text { for Scoliosis }\end{array}$} \\
\hline & At First Visit & $\begin{array}{c}\text { Before Surgery for } \\
\text { NAAs }\end{array}$ & $\begin{array}{c}\text { After Surgery for } \\
\text { NAAs }\end{array}$ & $\begin{array}{c}\text { Before Surgery for } \\
\text { Scoliosis }\end{array}$ & At Latest Visit & & \\
\hline 1 & 40 & 55 & 68 & N/A & 68 & $6 y 3 \mathrm{~m}$ & N/A \\
\hline 2 & 66 & 95 & 98 & 98 & 46 & $3.5 \mathrm{~m}$ & $4 y$ \\
\hline
\end{tabular}


Table 1. contd....

\begin{tabular}{|c|c|c|c|c|c|c|c|}
\hline \multirow[b]{2}{*}{ Case } & \multicolumn{5}{|c|}{ Curve Magnitude $\left({ }^{\circ}\right)$} & \multirow{2}{*}{$\begin{array}{l}\text { Length of Follow- } \\
\text { Up after Surgery } \\
\text { for NAAs }\end{array}$} & \multirow{2}{*}{$\begin{array}{l}\text { Length of Follow- } \\
\text { Up after Surgery } \\
\text { for Scoliosis }\end{array}$} \\
\hline & At First Visit & $\begin{array}{c}\text { Before Surgery for } \\
\text { NAAs }\end{array}$ & $\begin{array}{l}\text { After Surgery for } \\
\text { NAAs }\end{array}$ & $\begin{array}{c}\text { Before Surgery for } \\
\text { Scoliosis }\end{array}$ & At Latest Visit & & \\
\hline 3 & 20 & 20 & 12 & N/A & 12 & $5 \mathrm{y} 8 \mathrm{~m}$ & N/A \\
\hline 4 & 27 & 27 & 3 & N/A & 3 & $12 \mathrm{y} 3 \mathrm{~m}$ & N/A \\
\hline 5 & 30 & 30 & 64 & 64 & 24 & $8 \mathrm{y} 10 \mathrm{~m}$ & $1 \mathrm{y} 6 \mathrm{~m}$ \\
\hline 6 & 45 & 40 & 67 & 67 & 32 & $3 \mathrm{y} 2 \mathrm{~m}$ & $1 \mathrm{y}$ \\
\hline 7 & 70 & 70 & 68 & 68 & 47 & $2.5 \mathrm{~m}$ & $4 y 3 \mathrm{~m}$ \\
\hline 8 & 90 & 90 & 90 & 90 & 64 & $10 \mathrm{~m}$ & $5 y$ \\
\hline 9 & 41 & N/A & N/A & 63 & 27 & N/A & $1 \mathrm{~m}$ \\
\hline 10 & 28 & 28 & 23 & N/A & 23 & $4 y$ & N/A \\
\hline 11 & 24 & 24 & 19 & N/A & 19 & $3 y 5 \mathrm{~m}$ & N/A \\
\hline 12 & 48 & 48 & 56 & N/A & 56 & $2 \mathrm{y} 10 \mathrm{~m}$ & N/A \\
\hline
\end{tabular}

Table 2. Summary of Clinical Features of Neuropathic Scoliosis Caused by NAAs

\begin{tabular}{|c|c|}
\hline Clinical Features & Rate of Abnormality \\
\hline \hline Abnormality of abdominal skin reflex $*$ & $10 / 12(83.3 \%)$ \\
\hline Atypical inverted curve pattern & $5 / 12(41.7 \%)$ \\
\hline Younger age (less than 10 yrs) & $6 / 12(50.0 \%)$ \\
\hline Severe scoliosis (40 degrees or more) & $7 / 12(58.3 \%)$ \\
\hline Neurological symptom ** & $3 / 12(25.0 \%)$ \\
\hline
\end{tabular}

* laterality: 7 cases / loss: 3 cases

** motor dysfunction of right arm, acute left hemiplegia, gait abnormality

NAAs: neural axis abnormalities

Table 3. Comparison Between Neuropathic and Idiopathic Scoliosis

\begin{tabular}{|c|c|c|c|}
\hline & Neuropathic & Idiopathic & Statistics \\
\hline \hline Age (ave.) & $10 \mathrm{yr} 5 \mathrm{mo}$ & $13 \mathrm{yr} 10 \mathrm{mo}$ & $\mathrm{P}<0.001^{*}$ \\
\hline Gender (M / F) & $5 / 7$ & $22 / 250$ & $\mathrm{P}<0.001^{* *}$ \\
\hline Rate of female & $58.3 \%$ & $91.9 \%$ & $\mathrm{P}<0.001^{*}$ \\
\hline Cobb angle & $44.1 \pm 21.4^{\circ}$ & $35.2 \pm 11.0^{\circ}$ & $\mathrm{P}<0.001^{*}$ \\
\hline Thoracic kyphosis & $40.0 \pm 8.2^{\circ}$ & $24.9 \pm 10.6^{\circ}$ & \\
\hline
\end{tabular}

*unpaired t-test, $* *$ chi square test

by nonscheduled medical examination. With regard to initial treatment methods for scoliosis and the clinical course, surgery was performed in 3 cases, an under arm brace was prescribed in 6 cases, and observation was selected in 3 cases. All 4 patients who started brace treatment at $40^{\circ}$ and over became worse. Finally, 3 cases initially received brace treatment went to surgery and 1 case under observation switched to brace treatment due to worsening of curve magnitude. Surgeries for the relationship of NAAs were carried out for all cases, except a case of syrinx alone. Scoliotic curves were improved in 4 out of the 11 cases undergoing neurosurgical intervention. The Cobb angles measurement at initial presentation for these 4 cases were less than $30^{\circ}$ (Table 1). Moreover, 3 of the 4 cases were 8 years old or less. As for the typical findings of neuropathic scoliosis caused by NAAs, 10 cases showed the abnormalities of abdominal skin reflex, 5 cases indicated an atypical inverted curve patterns, 6 cases were diagnosed before 10 years old, 7 cases had severe curves over $40^{\circ}, 3$ cases had neurological symptoms, and 6 cases had thoracic hyperkyphosis over $40^{\circ}$ (Table 2 ).

The results of comparing about clinical features between neuropathic scoliosis caused by NAAs and idiopathic scoliosis patients is recorded in Table 3. Neuropathic scoliosis caused by NAAs patients included 5 boys and 7 girls with a mean age of 10 years and 5 months. Idiopathic scoliosis patients included 22 boys and 250 girls with a mean age of 13 years and 10 months (ranging in age from 4 years 
Table 4. Rate of NAAs by Screening Cervical MRI

\begin{tabular}{|c|c|c|c|c|}
\hline Reasons for Screening Cervical MRI & No of Cases & YES & NO & Rate of Abnormality \\
\hline Progressive curve $\left(40^{\circ}<\right)$ & 30 & 7 & 23 & $23.3 \%$ \\
\hline Younger age $(10 \mathrm{yr}>)$ & 17 & 6 & 11 & $35.3 \%$ \\
\hline Abnormality of abdominal skin reflex & 17 & 10 & 7 & $58.8 \%$ \\
\hline Unusual inverted curve pattern & 29 & 6 & 23 & $20.7 \%$ \\
\hline Triple curve pattern & 9 & 0 & 9 & $0.0 \%$ \\
\hline Neurological sign (numbness, paralysis) & 3 & 3 & 0 & $100.0 \%$ \\
\hline Others (headache, progression after matulity) & 4 & 0 & 4 & $0.0 \%$ \\
\hline All cases & 78 & 12 & 66 & $18.2 \%$ \\
\hline
\end{tabular}

NAAs: neural axis abnormalities

7 months to 30 years 4 months). Average initial Cobb angles of neuropathic scoliosis caused by NAAs and idiopathic scoliosis patients were $44.4 \pm 21.4^{\circ}$ and $35.2 \pm 11.0^{\circ}$, respectively. Average thoracic kyphosis of neuropathic scoliosis caused by NAAs and idiopathic scoliosis patients were $40.0 \pm 8.2^{\circ}$ and $24.9 \pm 10.6^{\circ}$, respectively. The neuropathic scoliosis group was younger in age, lower rate of female, predominant more in degree of magnitude, and had larger thoracic kyphosis than idiopathic scoliosis.

\section{DISCUSSION}

In the treatment of neuropathic scoliosis caused by NAAs, intervention in the relationship of NAAs should be given preference over that in the spinal deformity because neuropathic disorder is the main cause of scoliosis. Cardoso et al., [14] reported that a Chiari decompression leads to a reduction or resolution of the syrinx and may result in a concomitant improvement in scoliosis. Zadeh et al. [4] also stated that the primary and the most important step in the successful treatment of scoliosis with syringomyelia is early surgical decompression of the syrinx. Therefore, although it is critical to differentiate neuropathic scoliosis caused by NAAs from idiopathic scoliosis owning to lack of neurological signs, we should make efforts to accomplish early detection of scoliosis attributed to neuropathic disorders by turning up some specific clinical findings in neuropathic scoliosis caused by NAAs.

Abnormality of abdominal skin reflex is one of the most important features in neuropathic scoliosis caused by NAAs. Arai et al., [1] reported that abnormalities of abdominal skin reflex were shown in 36 of the $43(83.7 \%)$ of scoliosis patients associated with syringomyelia. Zadeh et al. [4] indicated that syringomyelia was discovered by MRI screening in 10 of the $12(83.3 \%)$ scoliosis patients who were loss of an abdominal skin reflex. In our clinical experience, spinal cord disorders were similarly discovered in 10 of the $17(58.8 \%)$ scoliosis patients who had abnormality of an abdominal skin reflex (Table 4) [15].

Most scoliosis patients presenting NAAs tend to be infantile or juvenile. Gupta et al. [5] reported that there were spinal cord disorders in 6 of the $34(17.6 \%)$ of juvenile cases and in 3 of the $6(50.0 \%)$ of infantile cases. Lewonowski et al. [6] mentioned that in 26 patients with idiopathic scoliosis under 11 years of age without neurological signs, MRI showed abnormal intraspinal pathology with Chiari malformation type I in $5(19.2 \%)$. Dobbs et al. [7] recommended a total spine MRI evaluation at the time of presentation for all patients with infantile idiopathic scoliosis who have a curve measuring $\geq 20^{\circ}$ because 10 of the 46 $(21.7 \%)$ cases with an age of 3 years or less were found to have a NAA on MRI. Evans et al. [8] also stated that MRI of all patients with scoliosis of juvenile onset should be performed on the basis of their prospective study in which 8 of the 31 patients aged $4-12$ years cases $(25.8 \%)$ had evidence of NAAs. In our current study, patients with neuropathic scoliosis caused by NAAs were younger than those with idiopathic scoliosis (Table 3 ).

Furthermore, atypical curve pattern, including left thoracic curve is an additionally characteristic feature in neuropathic scoliosis caused by NAAs. Arai et al. [1] reported that in their series, 15 of the 43 (34.9\%) scoliosis patients associated with syringomyelia had left thoracic curve. Muhonen et al. [11] indicated that 4 of the $11(36.4 \%)$ scoliosis patients with pediatric Chiari malformation exhibited a left thoracic curvature pattern. Charry et al. [9] reported 10 of the $25(40.0 \%)$ patients with scoliosis and associated syringomyelia had left thoracic curvatures which did not resemble typical idiopathic scoliosis. Coonrad et al. [10] advocated that the left thoracic curve in itself might indicate the presence of intraspinal abnormalities. In our clinical experience, 6 of the $29(20.7 \%)$ scoliosis patients with unusual inverted curve pattern showed abnormalities of spinal cord by cervical MRI (Table 4) [15]. However, Diabs et al., [12] recently reported that the thoracic hyperkyphosis $\left(>40^{\circ}\right)$ and juvenile onset $(\leq 10 \mathrm{yrs})$ were risk factors for NAAs, whereas, apex left thoracic curve was not recognized as an independent predictor of NAAs. Certainly, our results showed that neuropathic scoliosis caused by NAAs was younger age with larger thoracic kyphosis than idiopathic scoliosis. But it is still debatable with regard to the relation between the direction of the apex and the presence of NAAs.

Based on these characteristics conducted from previous and current studies, for early detection of neuropathic scoliosis caused by NAAs, we routinely perform a screening cervical MRI for the patients with scoliosis who meet the following conditions; under 10 years old, abnormal of 
abdominal skin reflex, atypical curve pattern, and progressive scoliotic curve over $45^{\circ}$.

The other points for early diagnosis of original NAAs related to scoliosis besides MRI screening are education of pediatricians about neuropathic scoliosis caused by NAAs and its features because they may have more opportunities to identify these younger scoliosis patients than spine surgeons. A more liberal use of MRI screening for all suspected younger idiopathic scoliosis patients may be effective. Winter et al. [16] and Do et al., [17] stated that routine MRI evaluation of neurologically normal adolescents with idiopathic scoliosis is not warranted from their clinical study and that few patients were noted to have an abnormality on MRI and no patient required a neurosurgical intervention or further evaluation. However, Cheng et al. [18] emphasized that some adolescent idiopathic scoliosis patients who had progressive deformity may have asymptomatic spinal disorders regardless of an age of onset.

Meanwhile, not only prompt detection but also early intervention in the relationship of NAAs is mandatory for favorable prognosis of neuropathic scoliosis. Eule et al. [19] repotered that early decompression of Chiari malformation type I with syringomyelia and scoliosis resulted in improvement or stabilization of the spinal deformity in 5 of the $5(100 \%)$ cases who underwent decompression before 8 years of age and before the curve was severe. Charry et al., [9] described that 5 of the 8 neuropathic scoliosis cases underwent neurosurgical treatment at age 8 or younger had no worsening or improvement of their scoliosis. Muhonen et al. [11] also reported on two scoliosis patients with Chiari malformation under 10 years of age who had resolution of their scoliosis, despite preoperative curves measurements of more than $40^{\circ}$. Flynn et al. [20] identified that progression of spinal deformity despite neurosurgical management of Chiari malformation was noted with older age at neurosurgical decompression and initial neuralgic symptoms, double scoliosis curve pattern, kyphosis, rotation, and large curve presentation. In our study, spinal deformities of the 4 cases on whom surgeries for the relationship of NAAs were performed at the Cobb angles less than $30^{\circ}$ were improved. Further, 3 of the 4 cases were 8 years old or less. On the basis of these facts, we presume early treatment for NAAs at young age below 8 years old and before curve progression under $30^{\circ}$ are essential points for desirable prognosis of neuropathic scoliosis caused by NAAs. With respect to treatment of scoliosis due to syringomyelia alone or syringomyelia associated with Chiari malformation, Phillips et al., [21] advocated bracing as a temporizing measure to delay a posterior spinal fusion, and Farley et al. [22] stated bracing was not effective in preventing curve progression. Therefore, corrective surgery may be warranted in management of scoliosis. In the cases of corrective surgery, they should be performed after neurosurgical treatment because forceful surgical correction of scoliosis in association with syringomyelia, without treating the underlying pathology, is potentially disastrous. There have been some reports of paraplegia and quadriplegia after a posterior spinal fusion without neurosurgical intervention [23-26]. Phillips et al. [21] suggested that intraoperative neuropathic injury might be due to direct compression on the dilated syrinx, vascular compromise from traction on the spinal cord, cerebrospinal fluid pressure changes, and adhesions. Diabs et al. [12] stated in his report that there were no neural and other complications in surgical treatment of neuropathic scoliosis if neural examination was normal. This is a highly controversial issue because neural complications can be extremely critical and difficult to reverse.

Unfortunately, the number of cases enrolled in current study was small. Therefore, further investigation using much more patients must be necessary to confirm the validity of our stories, but we believe that out study will contribute to some improvement for the future management of neuropathic scoliosis caused by NAAs.

\section{CONCLUSIONS}

In order to manage neuropathic scoliosis caused by NAAs securely, treatment for the relationship of neuropathic disorders should take precedence over that for spinal deformities. Early detection by cervical MRI screening, education for all physicians about the existence and characteristics of neuropathic scoliosis caused by NAAs is important. Prompt treatment of NAAs at younger age ( $\leq 8 \mathrm{yrs})$ and before curve progression $\left(<30^{\circ}\right)$ may lead to favorable prognosis of neuropathic scoliosis caused by NAAs.

\section{CONFLICT OF INTEREST}

The authors confirm that this article content has no conflicts of interest.

\section{ACKNOWLEDGEMENT}

Declared none.

\section{REFERENCES}

[1] Arai S, Ohtsuka Y, Moriya H, Kitahara H, Minami S. Scoliosis associated with syringomyelia. Spine 1993; 18: 1591-2.

[2] Baker AS, Dove J. Progressive scoliosis as the first presenting sign of syringomyelia: a report of case. J Bone Joint Surg 1983; 65B: 472-3.

[3] Citron N, Edgar MA, Sheehy J, Thomas DGT. Intramedullary spinal cord tumors presenting as scoliosis. J Bone Joint Surg 1984; 66B: 513-7.

[4] Zadeh HG, Sakka SA, Powell MP, Mehta MH. Absent superficial abdominal reflexes in children with scoliosis. J Bone Joint Surg 1995; 77B: 762-7.

[5] Gupta P, Lenke LG, Bridwell KH. Incidence of neural axis abnormalities in infantile and juvenile patients with spinal deformity; is a magnetic resonance image screening necessary? Spine 1998; 23: 206-10.

[6] Lewonowski K, King JD, Nelson MD. Routine use of magnetic resonance imaging in idiopathic scoliosis patients less than eleven years of age. Spine 1992; 17: S109-16.

[7] Dobbs MB, Lenke LG, Szymanski DA, et al. Prevalence of neural axis abnormalities in patients with infantile idiopathic scoliosis. J Bone Joint Surg 2002; 84A: 2230-4.

[8] Evans SC, Edgar MA, Hall-Craggs MA, Powell MP, Taylor BA, Noordeen HH. MRI of 'idiopathic' juvenile scoliosis: a prospective study. J Bone Joint Surg 1996; 78B: 314-7.

[9] Charry O, Koop S, Winter RB, Lonstein J, Denis F, Bailey W. Syringomyelia and scoliosis: a review of twenty-five pediatric patients. J Pediatr Orthop 1994; 14: 309-17.

[10] Coonrad R, Richardson WH, Oakes WJ. Left thoracic curves can be different. Orthop Trans 1985; 9: 126-7.

[11] Muhonen MG, Menezes AH, Sawin PD, Weinstein SL. Scoliosis in pediatric Chiari malformations without myelodysplasia. J Neurosurg 1992; 77: 69-77.

[12] Diab M, Landman Z, Lubicky J, Dormasn J, Erickson M, Richards $\mathrm{S}$, member of the spinal deformity study group. Use and outcome 
of MRI in the surgical treatment of adolescent idiopathic scoliosis. Spine 2011; 36: 667-71.

[13] King HA, Moe JH, Bradford DS, Winter RB. The selection of fusion levels in thoracic idiopathic scoliosis. J Bone Joint Surg 1983; 65A: 1302-13.

[14] Cardoso M, Keating RF. Neurosurgical management of spinal dysraphism and neurogenic scoliosis. Spine 2009; 34: 1775-82.

[15] Kuroki H, Inomata N, Chosa E, Tajima N. Neuropathic scoliosis caused by spinal cord diseases. J Spine Res 2011; 2: 1805-10 (in Japanese)

[16] Winter RB, Lonstein JE, Heithoff KB, Kirkham JA. Magnetic resonance imaging evaluation of the adolescent patient with idiopathic scoliosis before spinal instrumentation and fusion: a prospective, double-blinded study of 140 patients. Spine 1997; 22: 855-8.

[17] Do T, Fras C, Burke S, Widmann RF, Rawlins B, Boachie-Adjei O. Clinical value of routine preoperative magnetic resonance imaging in adolescent idiopathic scoliosis: a prospective study of three hundred and twenty-seven patients. J Bone Joint Surg 2001; 83A: 577-9.

[18] Cheng JCY, Guo X, Sher AHL, Chan YL, Metreweli C. Correlation between curve severity, somatosensory evoked potentials, and magnetic resonance imaging in adolescent idiopathic scoliosis. Spine 1999; 24: 1679-84.
[19] Eule JM, Erickson MA, O'Brien MF, Handler M. Chiari I malformation associated with syringomyelia and scoliosis: a twenty-year review of surgical and nonsurgical treatment in a pediatric population. Spine 2002; 27: 1451-5.

[20] Flynn JM, Sodha S, Lou JE, et al. Predictors of progression of scoliosis after decompression of an Arnold Chiari I malformation. Spine 2004; 29: 286-92.

[21] Phillips WA, Hensinger RN, Kling TF. Management of scoliosis due to syringomyelia in childhood and adolescence. J Pediatr Orthop 1990; 10: 351-4.

[22] Farley FA, Song KM, Birch JG, Browne R. Syringomyelia and scoliosis in children. J Pediatr Orthop 1995; 15: 187-92.

[23] Diaz JH, Lockhart CH. Postoperative quadriplegia after spinal fusion for scoliosis with intraoperative awakening. Anaesth Analg 1987; 66: 1039-42.

[24] Huebert HT, MacKinnon WB. Syringomyelia and scoliosis. J Bone Joint Surg 1969; 51A: 338-43.

[25] Noordeen MH, Taylor BA, Edgar MA. Syringomyelia: a potential risk factor in scoliosis surgery. Spine 1994; 19: 1406-9.

[26] Nordwall A, Wikkelsø C. A late neurologic complication of scoliosis surgery in connection with syringomyelia. Acta Orthop Scand 1979; 50: 407-10. 